\title{
FILOSOFÍA HISTORIOGRÁFICA E HISTORIOGRAFÍA
}

\section{J. Arturo Motta Sánchez*}

RESUMEN: El autor analiza el aporte del pensamiento ancilar bantú ecuatorial y su insensible dispersión en la mentalidad rural de los trabajadores novohispanos tanto indios, mulatos y negros criollos, apreciable sobre todo en las copias de jarabes cantados, y procesos inquisitoriales que pudo estar presente como elemento precursor, en los móviles eidéticos de la guerra de independencia.

Palabras Clave: Historia de la filosofía mexicana, Pensamiento en el periodo colonial, Pensamiento africano, Esclavos en México.

ABSTRACT: The author explores the contribution of the equatorial Bantu slave thinking and the way it was insensitively dispersed in the rural mentality of the workers of the New Spain, among indigenous peoples, mulattoes, blacks and criollos; which is evident in Mexican the copies of folk songs (jarabes) and in inquisitorial processes, and which could be a precedent element in the main motives for the independence war.

KEY WORDS: History of Mexican philosophy, Colonial period thinking, African thinking, Slaves in Mexico.

Para la fecha en que está en auge la empresa historiográfica de la filosofía en México, décadas de los cuarenta y cincuenta del siglo pasado, habían salido a la prensa, entre otros muchos productos del trabajo historiográfico no filosófico: la revista bianual Afroamérica, editada por el Fondo de Cultura Económica y el trabajo de Aguirre Beltrán, ${ }^{1}$ que, sin ser pionero en el tema sobre la población negra de México, era un compendioso afán que ilustraba la relevancia de ese importante sector demográfico y cultural del mestizaje en la Nueva España; obra que profundizaba en lo que años antes Alfonso Toro $^{2}$ pusiera de manifiesto en

* DEAS-INAH (motts@prodigy.net.mx).

1 Gonzalo Aguirre Beltrán, La población negra de México: estudio etnohistórico [1 ${ }^{\mathrm{a}}$, 1946] 2a , México, FCE, 1984 (Colección Tierra Firme).

2 Alfonso Toro, "Influencia de la raza negra en la formación del pueblo mexicano", Ethnos, núms. 8-12, México, 1920-1921, t.I, pp. 215-218. 
cifras derivadas de su indagación en los archivos españoles, al tiempo que Molina Enríquez elaboraba su diagnóstico sobre los problemas nacionales, en el que también se refería a la población afromestiza trabajadora de los cañaverales del estado de Morelos a principios del siglo Xx. Todos estos textos hacían hincapié en el peso y la trascendencia de esa población y de su descendencia para la Nueva España.

Los historiógrafos de la filosofía en México desconocían —o así lo infiero- a ese componente del mestizaje nacional, puesto que sólo consideraron a la mezcla de indio y español. El supuesto de que la raza cósmica de Vasconcelos sólo se forma de amerindio y europeo, desde luego, es falso, como bien han señalado diversos estudiosos de la población novohispana sucesora de africanos y, en particular, desde el punto de vista del análisis demográfico de Patrick Carroll. ${ }^{3}$ Como sea, los historiógrafos de la filosofía en México en su infructuosa búsqueda por hallar elementos de "modernidad" en el pensar novohispano, soslayaron de él, la presencia del pensamiento africano.

A pesar de su pretendido cosmopolitismo intelectual (y de la también supuesta peculiaridad de la filosofía mexicana), los historiadores de la filosofía en México no necesitaban haber leído a Gramsci ni a Eileen Power, ${ }^{4}$ para tratar de rescatar en sus investigaciones a los negros, mulatos y pardos novohispanos como forjadores de puntos de vista alternos o contrapuestos a los de las clases dominantes. Pero para observarlos o percibirlos así, hacía falta despojarse del prejuicio; hacía falta — parafraseando a Power— "rebajar la dignidad de la filosofía";

3 Patrick Carroll, "Los mexicanos negros, el mestizaje y los fundamentos olvidados de la 'raza cósmica': una perspectiva regional', Historia mexicana, México, COLMEX, 1995, v. XLIV, p. 3.

4 Profesora de la Escuela de Ciencias Políticas y Económicas de la Universidad de Londres, que en los años treinta del siglo xx publicó Gente de la Edad media (Londres, Penguin Books, 1937. /tr. Buenos Aires, Eudeba, 1996), obra que reivindicaba a los verdaderos hacedores de la historia; la masa anónima "e indeferenciada que descansa en tumbas ignoradas" pero merced "a cuya lenta faena prosperó el mundo". 
Algo difícil de pedir a la conciencia de clase de muchos de quienes en ese entonces asistían a la Universidad Nacional Autónoma de México a enseñar o a estudiar filosofía.

Por ese cartabón y esa conciencia de clase, los especialistas de la historia de la filosofía en México sólo buscaron y hallaron en sus universos de investigación lo que querían encontrar. Y se contentaron con saber y decir que sólo en el último tercio del siglo XVIII, los intelectuales novohispanos apenas estaban entrando a la modernidad, en proceso no exento de titubeos. Advirtiéndolo en la comprobación de un tímido desapego a los cánones novohispanos que subordinaban la filosofía a la teología, ya por el método de estudio empleado, ya por el tipo de objeto epistémico enfocado.

Si tales investigadores se hubieran ocupado de las clases subalternas, populares e iletradas — que han dejado testimonios en repositorios no académicos - habrían observado que muchos de sus integrantes desde bastante antes de la época arriba consignada mucho se apartaron del canon religioso; de modo que prácticamente eran "modernos". De hecho gestaron lo que sus encomiados intelectuales posteriormente digerirían y convertirían en "corpus político" discursivo y, a la postre, subversivo. Este fenómeno lo sugirió ya Villoro ${ }^{5}$ aunque nunca señale, ni como posibilidad, su punto de origen, aunque no deja de lado su atinada caracterización como ideología mesiánica.

Los rastreadores de huellas de modernidad en el pensamiento filosófico novohispano acaso, incluso, no habrían necesitado remitirse a repositorio documental alguno, si hubiesen tomado en cuenta lo que en la década de los años treinta, los musicólogos Gabriel Saldívar, Rubén M. Campos y poco después, Baqueiro Foster habían ya obtenido, apuntado, publicado y destacado en sus respectivas investigaciones sobre la historia de los géneros musicales del país, en torno a los aires indepen-

5 Luis Villoro, El proceso ideológico de la revolución de Independencia, $2^{\mathrm{a}}$ ed., México, 1966 [reimpr. 1977]. 
dentistas, como demanda de consumo cultural de las clases populares novohispanas en torno al último cuarto del siglo XVIII.

Así señalaron que, en los intermedios de los montajes teatrales en el Coliseo, la vox pópuli novohispana exigía reemplazar los sonecitos y tonadillas españolas, por los jarabes y sonecitos del país; muchos de acusada huella afroide en su rítmica, y de letras casi "ilustradas" en sus décimas, según lo probaron en sus investigaciones y posteriormente ratificaron otros etnomusicólogos. ${ }^{6}$

Respecto a la generación de sub-versiones novohispanas véase también el papel que desempeñaron los mancipos trabajadores de los ingenios azucareros - zonas de africana—, generando un ambiente propicio para forjar un modelo si no nuevo, sí reformador de aspectos del imaginario de los indios serranos que a esas factorías llegaban a laborar. Por ejemplo en Michoacán en los primeros treinta años del siglo XVIII este suceso se apreciaba:

en la aparición de ideas y actitudes que los defensores del buen orden social encontraban alarmantes. Los indígenas, lejos de la vigilancia de los curas párrocos, de los oficiales de república y del seguro pero rígido universo moral de los pueblos, en convivencia con los peones mulatos de las haciendas, como decía un funcionario, "se acostumbran insensiblemente a la vida libre que ofrecen los climas calientes." 7

Esta violación a las normas disciplinarias —normas que, supuestamente, debían imponer los mayorales o mandadores en los ingenios para

6 Gabriel Saldívar [Silva], Historia de la música en México, /colab. Elisa Osorio Bolio, Ed. Facs. de la de 1934. /Mario Colín, México, Biblioteca Enciclopédica del Estado de México, 1981. Rubén M. Campos, El folklore y la música mexicana, México, SEP, 1928. G. Baqueiro Foster, Historia de la música en México: la música en el periodo independiente, México, SEP, INBA, Depto. de Música Sección de Investigaciones Científicas, 1964.

7 F. Castro Gutiérrez, Virginia Guedea y J. L. Mirafuentes Galván, Organización y liderazgo en los movimientos populares novohispanos, México, IIH-UNAM, 1992 (Seminario de Rebeliones y Revoluciones en México, Serie de Historia Novohispana, 47), p. 52. 
reproducir, de algún modo, la relación rey-siervos - posiblemente sólo fuera el eco lejano de la cosmovisión africana bantú que prohijó el espíritu revoltoso manifestado en el movimiento del insurrecto Yanga, cuyas huestes, con sus repetidas incursiones, asolaron a los mercaderes y a las personas que transitaban el camino Real de Veracruz a México, en la segunda década del siglo XVII. O de los bozales africanos recién desembarcados que mataron a su traficante esclavista Acevedo. Cien años después transitaban por el mismo sitio los negros cimarrones del posterior asentamiento de Nuestra Señora de Guadalupe de los negros de Amapa ya fugos de los trapiches e ingenios azucareros de Córdoba.

También es probable que parte de esa cosmovisión bantú haya sido la que influyó en las visiones y expresiones de posesión del mulato Domingo Naranjo "cuya altura y facciones causaban temor entre los indígenas" pueblo; y de las que se valió el indio pueblo Popé para promover y acaudillar la rebelión contra los españoles en Nuevo México (1680). ${ }^{8} \mathrm{O}$ la de los “indios medio mulatos, casta de negros" de la ranchería de Cahuisorichi, cabecillas locales en 1690 formados en la dicha rebelión de $1680 .{ }^{9}$

En lo que sigue intentaremos plantear como hipótesis complementaria, un aspecto africano constitutivo de ese crisol de versión alterna o subversión, del pensamiento novohispano que, sin duda, nutrió de alguna manera el espíritu proindependentista.

\section{EL $N G A N G A^{10}$ JuAN GRANDE}

Mediante el examen de una acusación por hechicería, que se localiza en el ramo de Inquisición, hecha a principios del siglo XVIII contra el esclavo

8 M. González de la Vara, "La rebelión de los indios pueblos de Nuevo México, 16801693", en Castro Gutiérrez, op. cit., pp. 11-35.

9 Luis González Rodríguez, "Las guerrillas de resistencia étnica en el noroeste (1690). Un análisis de la documentación oficial”, en Castro Gutiérrez, op. cit., pp. 36-114.

10 Inyanga, mganga, sing'anga, nkganga, ngengan, son términos, entre varios otros similares, utilizados por muchas de las etnias bantú del África subsahariana, que 
bozal Juan Grande, ${ }^{11}$ se intentará esbozar ${ }^{12}$ cómo en el periodo histórico de los albores del siglo XVIII en la Nueva España, se trató un tema filosófico - si por él, con Platón y muchos otros, convenimos que la filosofía es el saber que procura ventaja al humano- el cual involucró a africanos y novohispanos descendientes de africanos, así como a novohispanos blancos (curas), en una discusión de tema religioso que anticipa, cronológicamente, al que se dio en la Ilustración francesa y, más tardíamente, con el por muchos denominado irracionalismo nietzscheano de la crítica a los valores de la modernidad. Esta última, la modernidad, objeto de búsqueda, afanes y preocupaciones de los especialistas de la historia de la filosofía en México, en tanto que algunos de sus temas fueron considerados como índice inequívoco de progreso "de lo mexicano" novohispano en el terreno del pensamiento occidental; luego, fue razón suficiente para soportar todo reclamo que intentara cuestionar la legitimidad y prosapia de los "modernos", pues para este propósito y no otro, la invocaban.

largo sería aquí enumerar, distribuidas por el lado occidental costero al Atlántico, por las que conocen a aquél detentador de saber. Así por ejemplo, "Zulu word inyanga, like our 'doctor,' covers a variety of meanings; properly it denotes a person skilled in any art or knowledge: a blacksmith, for instance, is inyanga yensimbi, "a doctor of iron." So the inyanga may be either a diviner or a herbalist, or both at the same time; possibly, also, a seer or prophet" dice Alice Werner, Myths and legends. 1933. En http:www.sacred-texts.com/afr/index.htm [bajado en 14/07/2002] en su capítulo XVI, "doctores, profetas y brujos". En otros términos, el nganga podría equivaler al demiurgo griego.

11 J. Arturo Motta Sánchez, "Un bozal en el ingenio de San Nicolás Ayotla, Teotitlán, Oaxaca", Dimensión Antropológica, año 8, vol. 22, mayo-agosto, 2001. Y “¿Huellas bantú en el nordeste del estado de Oaxaca?", en María Elisa Velásquez y E. Correa [coords.], Población y culturas con herencia africana en México. Retos y perspectivas, México, INAH, 2005 (Africanía, 1).

12 El documento se localiza en el ramo de la Inquisición del Archivo General de la Nación (AGN) de México, y sólo consta de cuatro fojas, en él se encuentra una acusación y declaración indirecta, manipulada, seguramente, por la denunciante, el cura redactor y amanuense. El desenlace del asunto se ignora al no haberse hallado la cabeza del proceso; si es que éste en algún momento se incoó. 
Expondré que la postura intelectual de ese esclavo "bozal"13 africano cuestionando la abyección que producía, según su parecer, el cristianismo en los hombres novohispanos se anticipó a la crítica decimonónica nietzscheana y, por ende, a la de la Ilustración.

Caracterización no del todo nueva, pues en sus trazos generales está ya delineada en lo escrito por Hegel en su texto de Filosofía de la Historia $^{14}$ cuando se refiere a la religiosidad africana, la cual tal vez copió del relato y apreciaciones que hizo el fraile capuchino Giovanni Cavazzi, sobre su viaje al África subecuatorial a mediados del siglo XVII. Y si bien mi interpretación del texto inquisitorial no es exhaustiva sí se acerca a esa caracterización general del tudesco, aunque de ninguna manera comparte su contradictorio, prejuiciado, superficial y etnocentrista juicio — efecto del que era Hegel ambiguamente consciente- de menoscabar al continente africano y sus pobladores, los cuales concibe como el reflejo de una conciencia inferior, ya que no poseen el conocimiento que el espíritu tiene de sí en su proceso de autoconocimiento.

Aceptar tal concordancia no supone de mi parte la aceptación de la cosmovisión y esquema hegeliano sobre la historia. Ni esta exposición desea "corregir" o "enmendar" esa visión axiológica. Tal y como lo han hecho muchos especialistas de la filosofía en México y hacen hoy filósofos africanos, ya que implicaría tener por bueno y razonable el argumento defensivo de rechazar o aceptar el lugar cultural que Europa u Occidente nos ha querido asignar, sin que los involucrados en ese afán intenten siquiera interrogarse por qué títulos o derechos Occi-

${ }^{13}$ Entrecomillado va el término bozal porque el esclavo ya no era bozal, tanto porque dominaba el castellano como porque ya llevaba casi veinte años residiendo en territorio novohispano, de modo que estrictamente el vocablo no convenía para su designación. Sin embargo, el documento lo consignó como bozal para señalar su procedencia africana y acaso, la prevalencia en su personalidad de su autóctono bagaje cultural.

${ }^{14}$ Saber que, para ser precisos, no era africano, así en general como Hegel supuso, sino entresacado o propio de una de las zonas más conspicuas de abastecimiento de esclavos bantú hacia la América; y en particular a la Nueva España en las cuatro primeras décadas del siglo XVII, a saber, del Congo y Angola. 
dente debe asignarnos un sitio, e incluso, ¿por qué debemos ocupar un lugar? Desde el momento en que estamos en el mundo no necesitamos de justificación. No suponerlo así, conlleva a la mendicidad de identificación. ${ }^{15}$

Y eso es precisamente lo valioso del caso de Juan Grande y de las revoluciones populares. No necesitan títulos para legitimarse, basta estar ahí: su actuar y su saber. Es lo que califica su ser, su fortaleza. El reconocimiento y su calidad es producto del contraste y confrontación en igualdad, ventaja o desventaja de fuerzas, eso es todo.

El esclavo que nos ocupa, Juan Grande, fue un nganga, es decir, un poseedor del saber africano, sabía de maleficios y porvenires, hacía objetos apotropaicos, entre otras muchas habilidades. Y sólo porque lo era, es que pudo desde su mirada confrontar el saber religioso popular novohispano, en este caso el de la mulata que le denuncia, y abrirle un panorama alterno: ¿bueno, óptimo, pésimo, malo, regular? No lo sé. Pero sí que fue contrario a lo que a ella le enseñó la catequización que recibió desde su infancia, ¿cómo ella lo resolvió? fue tema que en otro texto traté de explorar. ${ }^{16}$

Exponer este caso permitirá encontrar pistas para mostrar también, que las impugnaciones al status quo novohispano no necesariamente provinieron de la gente letrada, como en su momento lo creyeron algunos de los especialistas de la filosofía en México, a los que resultaba incuestio-

15 En efecto entrar en debate sobre si hay o no filosofía africana, (o mexicana) supone aceptar la premisa de la validez y vigencia ahistórica, absoluta o universal de los parámetros que tienen por EL PENSAMIENTO a una sola histórica y exclusiva forma de pensar. Pensamiento o discursividad que en realidad no es sino uno entre muchas. Tal discusión es bizantina, para quien tiene por cierto que el reconocimiento no se necesita para ser; sino porque eres, y cómo eres, te viene la alteroidentificación; que después en posiciones, virtudes, debilidades, coyunturas (económicas, políticas), etc., ésta mengüe, se enaltezca, envilezca, transforme, afiance, etc., es ineludible que suceda, pues eso es el estar ahí. Y ese estar no da lugar a esencialismo alguno, ése es el juego y lucha del recíproco reconocimiento, y por tanto histórico reconocimiento e identificación, y no la exhibición de tu debilidad.

16 Motta Sánchez, op. cit. 
nable que: "Sacudido por el europeo, e inclinado ya al mundo moderno, el hombre de la colonia va abriendo los ojos a una nueva concepción de la vida [...] [pues] Las nuevas ideas filosófico-políticas permean ya el ambiente del siglo y han hecho presa de sus tentáculos al colono ávido de nueva orientación". ${ }^{17}$ Por ello "[...] el hombre [novohispano] no pensaba [ya] sólo como hombre de fe, sino que comenzaba a pensar como ser social'. Apreciación bastante difícil de dilucidar, pues aun cuando el historiógrafo de la filósofía en los pocos momentos que osó transgredir el marco conventual y conceptual de los textos impresos, y buscó su información en otros lugares, tales como realizar trabajo de campo en archivos - como afanosa y diligentemente lo efectuó la recién citada, Pérez-Marchand ${ }^{18}$ hace ya cerca de 60 años - conservó su misma posición clasista acerca de qué es o debía ser considerada filosofía - es decir, no gramsciana, sino elitista - por lo que de nueva cuenta sólo entresacó como casos relevantes los que estaban impresos. Acto bien translúcido cuando la autora diferenció su estudio de otros que con el mismo tema se elaboraron en su época. ${ }^{19}$

17 Monelisa Pérez-Marchand, Dos etapas ideológicas del siglo XVIII en México a través de los papeles de la Inquisición, México, COLMEX, 1945, p. 132.

18 Ibid., p. 23.

19 En efecto, deslindando la singularidad de su trabajo como producto de escrutinio en fuentes de primera mano, señala Pérez-Marchand que aun los elaborados con esa misma perspectiva; como los de: "John Tate Lanning, Gabriel Méndez Plancarte y otros, [...] son trabajos que gravitan alrededor de lo que se desarrollaba en el seno mismo de la clase intelectual iberoamericana: los ponentes universitarios, los hombres de ciencia, los educadores, los filósofos, los virreyes preclaros, etc.; en fin, la clase cultivada". En cambio, "nuestro ensayo [sostiene la autora] no surge de las páginas de archivo de una Universidad, ni de las gacetas, ni exclusivamente de las expresiones de la clase privilegiada, sino del Archivo de la Inquisición. Y en éste giran revueltos, como en fantástico caleidoscopio, además de aquellos mismos individuos, eclesiásticos de alta dignidad, y frailes desconocidos; militares de rango y simples sargentos; marqueses, condes, y el hombre de la clase media; funcionarios de gobierno y peluqueros o 'vendedores de pomadas". No hay pues, castas en su trabajo. 
Situar así su objeto de estudio ni siquiera le permitió al historiador/ filósofo la intuición de incorporar a su acervo casos ágrafos de las clases subalternas (es decir, gañanes y esclavos así como individuos libres: mestizos, indios, mulatos, pardos, negros); aun cuando es seguro que esta documentación pasó por sus escrutadores ojos, dada la cantidad de volúmenes que Pérez Marchand señala revisó ${ }^{20}$ y que, como similares a estos, muchos otros casos perfectamente pudieron haber sido incorporados a su universo de estudio, tanto si el historiógrafo de la filosofía hubiera tenido un marco interpretativo que comprendiese el papel que desempeñaron las clases subalternas, como si sus contemporáneos no hubieran manejado la noción de filosofía de manera laxa a fin de justificar su misceláneo escrutinio de textos novohispanos.

Mas el juicio de Pérez Marchand es contundente:

Sacudido por el europeo, e inclinado ya al mundo moderno, el hombre de la colonia va abriendo los ojos a una nueva concepción de la vida [...] Para nosotros esa nueva actitud significa algo más que la reacción contra el principio de la autoridad establecida, como mera reacción al principio en sí. Es la plasmación de una conciencia de nuevas realidades de la vida, es el gradual abrirse de todo un mundo de horizontes desconocidos a una humanidad que, habiendo logrado una visión mayor, quiere iniciarse en el conocimiento de aquello que hasta entonces le había sido desconocido. ${ }^{21}$

Para este movimiento reconstructor del pensamiento filosófico que se dio en la época novohispana, con sus contadas excepciones, sólo fue importante el pensamiento de matriz europea; ideas diferentes no merecieron ser tomadas en cuenta. En las excepciones, se podría mencionar al doctor León Portilla por lo que se refiere a la matriz indígena prehispánica; así como L. Villoro, quien señaló que el mundo ideológico

${ }^{20}$ La sorprendente cantidad de 685 volúmenes, que fueron del 711 al 1396; donde el caso exhibido por este texto, está comprendido justamente en el volumen 713 del ramo Inquisición.

${ }^{21}$ Pérez Marchand, op. cit., p. 142. 
del movimiento de la revolución de Independencia resultaría ininteligible si sólo se atendiese para su explicación y comprensión la matriz europea y las características de su recepción.

Del pensamiento de origen africano, proveniente de la mente de individuos singulares que llegaron entre los grandes contingentes y que se asentaron en las esclavonías de minas, trapiches o ingenios, estancias ganaderas y obrajes de la Nueva España, quiero destacar, ${ }^{22}$ en particular, el de raíz bantú. Las referencias sobre los negros bantú — de los cuales no se tenía la menor sospecha de su existencia debido principalmente al casi nulo conocimiento que se tenía de su cultura- aunque dispersas, pueden ser generalmente encontradas en los procesos judiciales e inquisitoriales.

El objeto de estas líneas es dar a conocer de manera más amplia algunos elementos del pensamiento de los negros esclavos de origen bantú. Para ello es necesario, por tanto, señalar algunas de sus principales características: 1) es un hecho que entre los esclavos africanos del siglo XVII en la Nueva España hubo poseedores del saber metafísico bantú - si esto es filosofía, o no, es tarea de quienes se dedican a ella determinarlo. 2) Por los datos consignados en la denuncia presentada al Santo Oficio sobre el esclavo bozal Juan Grande, se puede inferir que sus creencias se oponían al credo novohispano, y por tanto resultaba un elemento inquietante para las conciencias que le escuchaban; causa por la que, precisamente, se le denunció ante el Santo Tribunal de la Fe ${ }^{23}$ Paralelamente a estos procesos también existen algunos esclavos bozales blasfemos que se autodenuncian, ésta era una práctica

22 Los descendientes africanos también formaron parte de las tropas insurgentes, como de las de sus adversarios: los batallones realistas, recuérdese el de Yermo o los fusileros negros de Dambrini; o sus antecesores represores de la rebelión de Cancuc en Chiapas.

23 Esta situación también se presenta en otros procesos como el siguiente "contra Teresa, negra ladina, que reside en la venta de Tesmelucan, por decir "que el rey nuestro señor y los inquisidores y los frailes le besasen ciertas parttes" o contra "Lorenzo, negro, por decir "Dios y todo el mundo miente", o el testimonio contra un negro "llamado por mal nombre chicaco o chacuaco, esclavo del capitán Martín de Betra, 
común en los negros sevillanos y los del Brasil; lo consideraban un acto de doble resistencia al privar al amo del goce de su trabajo al quedar en las mazmorras, por una parte, y por la otra, la de continuar manifestando una práctica cultural propia "africana" que es la de imprecar a los númenes para obtener algo. ${ }^{24} 3$ ) Que por el contenido y efectos que se derivan de la denuncia hecha por Michaela ante la Inquisición, puede decirse que se anticipa por muchos años a la crítica que se hizo a la religión católica en la Ilustración y por Nietzsche. 4) Que es factible hacer una hipótesis con base en esta información dispersa sobre ciertos estratos sociales y culturales populares novohispanos; ${ }^{25}$ después de lo cual puede afirmarse que una parte de la cosmovisión hispana católico/romana, propia de las diversas fracciones de la clase dominante, que trata sobre el papel que le toca desempeñar al hombre en el mundo (deberes, recompensas, castigos, destino, etc.), resultó cuestionada y con innumerables burlas en décimas exclamadas en sones, valonas y jarabes propios de las incontables verbenas populares de la época colonial tardía, aspecto ya mencionado por los musicólogos Gabriel Saldívar, Baqueiro Foster, Mayer-Serra o el antropólogo Aguirre Beltrán ${ }^{26}$ en su texto intitulado Bailes de negros. 6) Que casos como el de Juan Grande, de ser rescatados por los especialistas de la filosofía en México hubieran cambiado o por lo menos permitido interrogar por la pertinencia

por haber quemado a un cristo". AGN, Inquisición, año 1601, vol. 255, exp. 5. Y AGN, Inquisición año 1602, vol. 256, exp. 151. AGN Inquisición, año 1615, vol. 308. exp. 22.

24 Véase por ejemplo AGN, Inquisición, año 1606, vol. 471, exp. 52. "Esperanza, negra bozal, contra si misma, por haber blasfemado de Dios y de sus santos. México". O, el exp. 110 de ese mismo volumen y año, "denunciación que de si misma hace Francisca, negra criolla esclava de Alonso de Villanueva, por haber renegado de Dios". M. Priore y Venancio Pinto, Ancentrais: uma indroducao a historiada Africa Atlantica, Río de Janeiro, Elsevier, 2004.

25 Gañanes, tlaquehuales, meseros —o alquilados por mes-, mineros, arrieros, plebe, desharrapados, todos ellos: indios, mulatos, o mestizos o pardos y algunos negros y castizos.

26 "Bailes de negros", Revista de la UNAM, vol. 25, núm. 2, octubre, 1970, pp. 2-5. 
de su tarea, que sólo se afanaban en buscar una veta fundante para la producción intelectual sobre el México colonial, es decir, la de matriz europea y de los autóctonos novohispanos. 7) Incorporar casos como los de Juan Grande podrían haber llevado a los historiógrafos de la filosofía "mexicana" de la época colonial a plantear las nociones de "filosofía”, de "intelectualidad", "Ilustración" en México, sea modificándolas o desechándolas, de tal manera que con ello los filósofos efectivamente sí habrían producido "fillosofía autóctona", y no sólo habrían buscado el reconocimiento. Acaso hubieran entrevisto, como bien lo señaló G. Aguirre Beltrán en el texto recién citado, que "parece como si el racionalismo de la Ilustración hubiese usado el canal de la copla para dar rienda suelta a su anticlericalismo" y, por ende, habrían hallado allí un indicador seguro de la modernidad en el pensar novohispano, que tanto han perseguido.

Por último, y sólo basándome en lo anterior diré que: 8) merced a resultados de trabajo de campo que realicé en pueblos indígenas de la Mixteca Alta oaxaqueña, encontré información en torno a las calidades shamánicas de la población negra de la costa chica oaxaqueña, donde para los mixtecos todos los "negros son brujos". Otros datos documentales que localicé hacen posible interpretar que los indígenas le atribuían cierto rasgo/percepción a Morelos, mulato insurgente, pues se le consideraba como un singular mesías, y ello fue posible gracias a la percepción analógica y tradicional que el imaginario de esas clases populares poseían sobre este singular "saber", seguramente heredado de generaciones anteriores y que formaba parte de su patrimonio cultural, por lo que consideraron que Morelos $^{27}$ tenía este saber y poder; dejo de cualquier bozal nganga africano.

Además de esta percepción sobre Morelos que tenía la gente, también poseía la investidura de sacerdote, curador de almas de Cuarácuaro. Desde esta perspectiva sería interesante profundizar en la biografía del insurgente Vicente Guerrero, también descendiente de africanos.

${ }^{27}$ Lucas Alamán, Historia de México, $3^{\text {a }}$ reimp., México, Jus, 1942, t. II, p. 339. 
Según lo anterior, podría ser factible que "elementos" de la cosmovisión africana bantú tuvieran bastante que ver no sólo con las variantes en el "clima" popular al que se refería Pérez Marchand, que hizo posible en la Nueva España la selección rigurosa de lectura y reinterpretación hecha por barberos, capitanes de milicia, o bajo clero, etc., de textos filosóficos provenientes de la Europa, sino, que también, con la aparición de estos "elementos" se conformó el sustrato que refiere Luis Villoro, ${ }^{28}$ el cual hizo que concepciones "Ilustradas" como la del padre Hidalgo se neutralizaran, dado el empuje mesiánico del común o populacho.

"Ya el infierno se acabó; ya los diablos se murieron; ahora sí, chinita mía, ya no nos condenaremos" rezaba una copla del Pan de Jarabe capturada por el Santo Oficio y que cantaba "el común" del hoy estado de Hidalgo por ahí de 1770 y que Gabriel Saldívar ${ }^{29}$ citó en su estudio sobre el origen del Jarabe. La irreverencia, no sólo anticlerical, que se trasluce en esas letras contra principios del credo católico - pues de inicio se niega la existencia del infierno- es contundente, y eso que era la época cuando más se insistía en asociar, por parte de la élite civil y religiosa, a la corona con la religión.

El "populacho", es decir, la sabiduría popular descalificó si no todo el credo, sí algunas partes importantes, y para ello no necesitó leer o citar a los Ilustrados.

¿Cuánto de esta actitud pudo deberse a "elementos" del saber africano? es algo casi imposible de conocer, particularmente por la ausencia de información directa en la documentación; aunque sí es posible sugerir, pues algo de esos testimoniales sobrevive aún, precisamente en fuentes como las de la Inquisición u otras de carácter judicial. Es el caso de Juan Grande.

28 Villoro, op. cit.

29 Gabriel Saldívar, "El jarabe, baile popular mexicano" [s.p.i.] [nota al pie del autor: "sirvió de base a esta monografía la conferencia sustentada por el autor en la Sala de Conferencias y Conciertos del Palacio de Bellas Artes, el día 30 de noviembre de 1934]. 


\section{EL DOCUMENTO FUENTE}

El expediente que se encontró trata de una denuncia que hizo, en mayo de 1700, Michaela de Ariza, mulata libre de Teotitlán del Camino Real, Oaxaca, ante Andrés de la Parada Sandoval, cura de la parroquia cabecera de San Miguel Arcángel y encargado de los asuntos del Santo Tribunal de la Fe de dicho pueblo. La denunciante acusa a Juan Grande, esclavo bozal, ${ }^{30}$ de haberla "enhechizado"

Después de examinar este documento, ${ }^{31}$ se puede señalar lo siguiente: 1) Aunque la denuncia no consigna el lugar de origen del esclavo Juan Grande, es posible inferirlo por el calificativo de bozal, en general este adjetivo en la época novohispana se aplicaba a los recién llegados del continente africano, en particular a los esclavos que no sabían el castellano, o se les dificultaba su pronunciación y prevalecía en ellos aún su cultura autóctona. 2) Por los elementos posológicos enlistados por la mulata cuando describe al cura y amanuense el método empleado por el bozal para curarle el dolor de caderas, también fue posible, confirmar el origen del esclavo, y suponer, con alto grado de certidumbre, que dicho Juan Grande no era un esclavo ordinario, sino poseedor de un saber especial, es decir, el propio del nganga o especialista en la analépsis del cuerpo social del África bantú. 3) Poseedor de este saber, el africano o nganga contó con elementos para cuestionar y rechazar los principios de la religión católica y las creencias de la sociedad novohispana. 4) Por tener una visión distinta a los procesos etiológicos que se tenían en el virreinato de la Nueva España (excluyamos a los de la cosmovisión indígena), en particular, nos referiremos a los de

30 Esclavo propiedad del ingenio de "hazer azúcar" de San Nicolás de padres jesuitas, ingenio perteneciente al colegio y "casa de nobicios y probación" de San Andrés de la Ciudad de México. Institución azucarera que he estudiado en otros textos. Véase J. Arturo Motta y María E. Velásquez, "El retablo de Ayotla..., ¿obra del mulato esclavo carpintero...", Antropología, Boletín INAH, Nueva Época, núm. 60, octubrediciembre, 2000.

31 AGN, Inquisición, vol. 713, exp. 57. Motta Sánchez, op. cit. 
salud/enfermedad, el nganga con sus conocimientos y el contacto que tuvo con la sociedad novohispana le permitió barajar diversos diagnósticos y posologías, por lo que su opinión y acciones adquirieron relevancia social entre sus pares fenotípicos. Esto no implica que pueda llegar a conocerse el grado de aceptación o rechazo ${ }^{32}$ de sus doctrinas entre sus contemporáneos. Basta con decir que su presencia no era indiferente a las esclavonías criollas, así como también a los libres y a los libertos, como se comprueba por la deferencia que se les tenía a los bozales en los ingenios azucareros cubanos. ${ }^{33}$

\section{UN POCO DE HISTORIA}

Los "representantes" de los denominados bantú del África subsahariana: los nganga, especialistas poseedores de diversos saberes, incluidos entre ellos los de médicos tradicionale ${ }^{34}$ del proceso salud/enfermedad, arribaron a la Nueva España a través de la trata de esclavos atlántica. ${ }^{35}$ Los mancipos llegaron "con su alma en boca y huesos en costal" a tierras novohispanas en virtud de la demanda y reglamentación regia; principalmente desde que se produjo la unión de las coronas lusa e ibera, en el año de 1580.

32 Incluso me atrevería a sugerir, lo que después habría que probar, que la rebelión de Yanga de 1615, en realidad no fue de Yanga, o Nanga, como en otras ocasiones se le consigna, sino del Nganga.

${ }_{33}$ Miguel Barnet, Biografia de un cimarrón, México, Siglo XXI, 1978.

34 Se le conoce por el nombre de nkganga entre los Mongo, nganga entre los Luba, Kongo y Fang, Bambwe, y ngengang entre los Ngoe, Yande, Evuzok, y otros pueblos del sur de Camerún; Zaire, Gabón, etcétera.

35 En la que participaron portugueses, holandeses, franceses e ingleses y banqueros, principalmente de origen judío establecidos en esas naciones, para la cual contaron con la colaboración de reyes negros costaneros indígenas que hacían la guerra a los reinos vecinos del interior para capturar esclavos "habidos de buena guerra y no de paz", esto por lo que respecta a la oferta de mano de obra barata; y por lo que respecta a la demanda, ésta se hizo por parte de súbditos colonos: lusos, iberos e ingleses, franceses y holandeses. 
Las gruesas remesas de esclavos que se enviaban en naos y navíos al reino de la Nueva España terminaron hasta un poco antes de concluir la penúltima década del siglo XVII, aunque este decrecimiento había iniciado al separarse Portugal de España en 1640. El destino de estas personas en tierras novohispanas fue trabajar en zonas urbanas como esclavos domésticos, o en obrajes o talleres de manufactura para producir telas, sombreros, o calzado entre otras mercancías; o bien, se les destinaba al ámbito rural: a minas como las de Pachuca, Zacatecas, Taxco, u otras; o haciendas ganaderas principalmente enclavadas en las zonas costeras, y como insumos productivos para las factorías de producir azúcar: ingenios o trapiches. Los "zangarros" fueron demasiado pequeños o entidades de poca monta, como para costearlos y mantenerlos.

Así en diversas remesas y tiempos llegaron esclavos transportados desde el Congo y Angola a todos los ingenios del reino novohispano, como al de "hazer azúcar" de San Nicolás, situado en la alcaldía mayor de San Miguel Teotitlán del Camino Real del Obispado de Oaxaca, (hoy conocido como parte de La Cañada). Entre ellos llegó Juan Grande, incorporado en 1680 .

Ingenios y trapiches se tornaron zonas interculturales de indios, mulatos, negros africanos y negros criollos libres o esclavos, con algunos españoles y contados ingleses, funcionarios de la cadena de mando; zonas cuyo clima multicultural incomodaba las conciencias de "los defensores del buen orden social" de la Nueva España, como bien, se dijo ya, lo ha señalado Castro Gutiérrez ${ }^{36}$ para Michoacán a principios del siglo XVIII, pues su efecto se manifestó no sólo en el ambiente del cañaveral sino, también, en la transformación del carácter de los indios jornaleros.

La hipótesis que propongo con base en esta delación a la Inquisición es la siguiente. Parte del cultivo de ese clima multicultural estuvo alimentado por la gnoseología del africano nganga y su difusión.

${ }^{36}$ Castro Gutiérrez, op. cit., p. 52. 
Lo cual se podría caracterizar en general como el poder que tienen ciertos hombres para dominar y cambiar el curso del mundo. ¿Cómo? Por medio de conjuros, herbolaria, invocando u obligando al mundo numinoso mediante la lógica ritual del intercambio simple, entre otros métodos. A este respecto apunta contundente el jesuita nganga contemporáneo Eric de Rosny: ${ }^{37}$ el nganga tiene una mística de combate y no de contemplación, [cursivas mías] pues lucha contra lo proveniente del ndimisi. Y reitera: "La mística africana nada tiene de contemplativa, como se entiende en Oriente, es decir, caracterizada por el predominio de la admiración y adoración, sino que se revela más bien activa, combativa, comprometida". El africano "no sube al cielo para gozar allí en paz de la visión beatífica. Más bien obliga a Dios a volver a la tierra[...]." 38

Hegel lo resumió bien cuando dijo que los poderes de la naturaleza si bien son reconocidos por el africano como tales, para los nganga, a los que llama hechiceros, "no son poderes que obedezcan a una ley eterna, a una Providencia; no constituyen una fuerza fija, universal, de la naturaleza[...] [lo cual escandalizaba al tudesco, ya que en esta concepción $]$ El hombre es señor sobre estos poderes naturales[...]" " "[...]no ruegan a Dios; no se dirigen a una fuerza superior, sino que creen que por sí mismos pueden efectuar lo que quieren". 39

De ahí concluía el portavoz del espíritu absoluto, que tal paradigma no era otra cosa sino la prueba palpable de su primitivismo, incapaz de remontarse a algo más allá del exclusivo e inmediato "ahí". Y que aun cuando el uso de talismanes y fetiches pareciera autorizar la opinión de que habrían superado su inmediatez, para atisbar algo similar al reconocimiento de una entidad superior, es decir, llegar a la

37 Éric de Rosny, Ojos que ven en la noche: un jesuita iniciado en la tradición africa$n a$, tr. de J. M. López de Castro, Herder, 1998, 267 pp.

${ }^{38}$ Historia de las religiones: los pueblos sin tradición escrita, México, Siglo XXI, 1982, t. II, p. 48.

${ }^{39}$ Hegel, op. cit., p. 196. 
abstracción; resulta que, como a sus fetiches los desechan o vituperan si no logran alcanzar el fin para el cual se les solicitó y manufacturó, ello era índice categórico para Hegel de que seguían sometidos al vaiven de lo contingente, al reino de la arbitrariedad, de la naturaleza, pues no habían tenido la capacidad de reconocer lo Absoluto en sí, Necesario, etc. Por ello sentenció "Los africanos, pues, no superan su propio capricho".

Esta osadía de la mística africana, que Hegel tuvo por defecto, y por ello la censuró con mentalidad de súbdito que desea erigir su opinión como rasero frente al cual todos los demás deben adherirse, será la meta tiempo después, entre otras, para Nietzsche. La autovaloración del individuo, fundada sobre sí mismo, el alcanzarse a sí, como fuente autónoma de sí, ése es y será el propósito de la posología nihilista.

Y efectivamente esta autovaloración de lo humano, como sabiduría del nganga africano, fue el paradigma que presidió la teoría general etiológica enunciada por el bozal al decirle a Michaela de Ariza, la mulata novohispana que fue a consultarle para que la curara de su enfermedad, que ésta, su enfermedad, llegaba de tierra africana, porque allá "matando aves blancas en los caminos, enviaban para acá las enfermedades", o en otras palabras, que la enfermedad que padecía resultaba producto de quehaceres específicos y determinados por hombres singulares y para específicos fines. Acaso, incluso, podría sospecharse, en términos de lectura novohispana, para tomar revancha de su calidad de esclavo.

Con ello no hacía otra cosa más que, por una parte, dañar la creencia de la mulata Michaela de que estaba enferma porque esa era la voluntad de Dios, credo que se expresa unánimamente en todas las cabezas de testamentos de muchos moribundos novohispanos, los cuales se pueden encontrar en los archivos notariales y ramo de testamentarías, quienes atribuían su estado a la "enfermedad que Dios se ha servido enviarme". Todo dependía de la Divina Providencia. Los hombres novohispanos, como en Homero, ante tal enunciación testamentaria, resultaban peleles de la volición divina. 
Por otra parte, y paralelamente a ese acto, el bozal anuncia que sabe diagnosticar y, por tanto, curar en términos del universo simbólico de su tierra "África", lo que lo eleva sobre sus demás congéneres en tanto tiene el poder sobre la vida al evitar, con su indiferencia o su actuar, la muerte. La muerte, nada, o fin total desde este enfoque no proviene de la acción divina cristiana, sino que es producto humano, de la acción del nganga. Por eso la muerte no es natural; lo que, también, vale un reproche hegeliano, aunque no lo hace a los cristianos, quienes también tenían a la muerte por obra sobrenatural, pues ésta dependía de la decisión divina.

Para el bozal Juan Grande todo esto no tenía sentido porque el católico novohispano ponía su fe en elevar preces a "Dios Nuestro Señor" para evitar la muerte. Por eso, y otras cosas más, le dirá a la mulata, que para él "no es bueno rezar". Para él los hombres, vivos o muertos, son siempre agentes causales; no hay azar. El actuar y la conducta son obra de hombres. Por lo demás esta ética implícita, impide eludir la responsabilidad humana, como sí sucede con el cristianismo (Kierkegaard aparte) y el protestantismo.

Y es justamente esa valoración, ese señorear del hombre por lo que a Hegel le pareció censurable la hechicería, y lo que de inmediato hará la diferencia entre el credo cristiano y las creencias del bozal. Credo que se le inculcó al vasallo novohispano, con mayor o menor éxito, y cuya finalidad fue siempre que su "individualidad" estuviera sometida a ambas majestades: la Divina y la temporal.

Este bagaje cultural, o sentido de la personalidad novohispana sometida y disminuida, es justamente lo que el nganga pondrá en tela de juicio, con base en las creencias en las que se levanta la cosmovisión de su saber; la valoración del yo humano como fuente primigenia de poder. De modo que "No hay, en el pensamiento africano, la idea de una finalidad fuera del ser humano". ${ }^{40}$ Preanuncio del nietzscheano Su-

${ }^{40}$ La Historia de las religiones..., resume el pensar metafísico africano subsahariano como sigue "¿no se trata, en definitiva, de una filosofía o una metafísica, o más bien 
perhombre profetizado por Zaratustra? Concepción humanista del bozal que por lo demás claramente se manifiesta en el hecho de que su método de curación tiene alcance universal; lo mismo puede curar en África que en la tierra de adopción forzada: América.

Es precisamente también ese valor universal lo que en primer término permite a Juan Grande degradar la ominipotencia de Dios ante la mulata al preguntarle ¿"no dice Dios, ayúdate, que yo te ayudaré?" Lo que a los ojos del esclavo era muestra evidente de la fragilidad divina o de su innegable origen humano — si es que aceptamos, por lo demás, que en efecto, Juan Grande lo tuviese por divinidad. Lo que por otra parte estaba perfectamente acorde con la conceptualización bantú de las relaciones entre los planos del mundo el numinoso de los nkises o espíritus, y el terreno de los humanos. Los primeros avatares de los ancestros para lograr comunicarse con los humanos, guiarlos espiritualmente para que continuaran existiendo requirieron forzosamente de la memoria humana, lo que aún puede observarse en los ritos afrocubanos, haitianos o afrobrasileños de la bajada del santo. Tal interpretación del poderío humano, bien pudo suscribirla Nietzsche cuando apuntó: “¿Cómo?, ¿es el hombre sólo un desacierto de Dios? ¿O Dios sólo un desacierto del hombre?"

Para el africano subsahariano muy por el contrario del Cristo novohispano, el supremo creador Ndzambi está tan alejado o es tan grande y excelso que cualquier disquisición acerca de su naturaleza, por principio o definición, excede o rebasa todo posible entendimiento, de modo que es el ser inefable. Como piensan los Maiacas de Angola: que al no saber de cierto quién es, dónde mora, ¿cómo pensar en invocarlo? Para esos menesteres de lo terreno están, justamente, los ancestros, seres que fueron humanos y se encuentran en otra dimensión, a los cuales

de una especie de humanismo que, partiendo del hombre para retornar a él, capta en su trayecto todo lo que no es él mismo, todo lo que constituye su superación?", p. 35 . 
el hombre puede presionar mediante conjuros, ritos, etc., para alcanzar el propósito anhelado.

De modo que, según lo anterior, atender o solicitar a la deidad no es importante para la comprensión y modificación de la actividad humana porque para el numen el hombre siempre le resultará indiferente. De ahí también que sea un sinsentido otorgar algún papel a la Providencia y a su mundo predeterminado. La deidad no se preocupa de los hombres. Son éstos los que deben ocuparse de sí mismos, para conservar la fuerza vital o $n^{\prime} t u$ que les permita su estar ahí o Ser en el mundo. De tal modo que no existe para el bozal Nganga la fatalidad de la "necesidad". Con tales creencias, justamente, se minaba la comprensión del mundo cristiano como predeterminado, y se ofrecía una visión que posibilitaba su fisura, en tanto muestra a los hombres árbitros de su destino, bueno o malo.

Las causas de placeres y displaceres en la tierra provienen no de la veleidosa voluntad de la divinidad, sino de la práxis humana. $Y$ es por eso que hay que actuar, saber, conocer, es decir, poseer sabiduría. Para obtener esto son los ritos iniciáticos. Lograr ser un nganga, si no de cuatro ojos ${ }^{41}$ por lo menos sí cercano, posibilita efectuar predicciones, y de alguna manera, garantiza certidumbre, exitosa o fallida, en el actuar cotidiano.

De quien hay que ocuparse, pues, no es de la Deidad, sino de los hombres antecesores o ancestros para que mediante las adecuadas exequias, libaciones y ofrendas, éstos entren a formar parte de la numínica extensión ${ }^{42}$ clánica, que brindará protección a su contraparte terrenal vía la transmisión de la sabiduría que redundará en la reproducción y acrecentamiento de la fuerza vital de la comunidad; sintetizada en que a más vitalidad más poder.

41 Luis Mallart, "La medicina popular africana", en Las razas humanas, Compañía Internacional Editora, 1984, vol. 3. Rosny, op. cit.

42 "La idea de la muerte en la vida africana", en Y. K. Bamunoba y B. Adoukounou, La muerte en la vida africana, Barcelona, Serbal, UNESCO, 1984. 
Pero si no se cumple el trato por cualquiera de las partes, como siempre sucede entre humanos, sobrevendrá el castigo pues se ha faltado a la reciprocidad. De modo que todo sucede y permanece entre pares.

Dada la certeza de que Ndzambi no se entromete en el mundo humano, para el bozal es extremadamente difícil creer en el Dios cristiano; porque éste, se supone, compele a los hombres a la inacción, a la pusilanimidad, a la servidumbre del pensar y del actuar pues la gente de la Nueva España sólo "espera en Dios". Es decir, es del todo pasiva, aguardadora. El acto de rezar para solicitar los divinos favores, es ejemplo de ello.

Por eso Juan Grande argumenta a Michaela: “[...] que en su tierra no esperaban en Dios, y para todo tenían remedio, que para sembrar milpas, si faltaba agua, ponían ollas de agua con llerbas en las quatro partes dellas, y que en herbiendo, llobía; y assí tenían remedios para las demás cosas".

Por eso, razonaba Hegel: para el africano, "el hombre se considera a sí mismo como lo más alto que puede dictar órdenes". ¿Algo más afín a lo que posteriormente señalará como digna meta el psicofisiólogo Nietzsche, en su afán de transmutar los valores de la modernidad?: "Cuál puede ser nuestra única doctrina? -Que al ser humano, nadie le $d a$ sus propiedades, ni Dios... en la realidad falta la finalidad".

Justo ese autovalorarse del bozal fue lo que más infundió temor a Michaela y le contradijo estupefacta, cuando éste le dijo que para protegerse usaba de un anillo de cobre:, "no seas tonto, mira lo que dices, Dios no necessita de que le ayudemos, sino que Dios nos ayuda a nosotros".

Sin que pretenda yo sintetizar de modo reduccionista la temática sobre la cual trata la obra de Federico Nietzsche, no se negará que uno de los motivos más persistentes en ella fue el de su acusación al cristianismo, de que hace de los hombres eunucos en muchos sentidos. Ello de inmediato se destila en Aurora, La genealogía de la Moral, Ecce homo, El Anti Cristo, entre otros títulos.

Entre otras inconsistencias, esa lectura y tendencia del cristianismo fueron detectados, tanto así que hubo credos contrarios que se levantaron 
en la Nueva España provenientes del mundo numínico de los nganga bantú tales como el de Juan Grande, y mucho antes de que lo hicieran los Ilustrados y Nietzsche. He aquí pues, evidencia, por una parte de la riqueza que la multiculturalidad ofrece para el desenvolvimiento humano y contra el poder, de manera general. Y para ser o estar, no se necesita de reconocimiento alguno, sino que éste se forja en la lucha por las representaciones. Por lo que toca a estas líneas, puedo decir que en el caso concreto del nganga Juan Grande y para el proceder de la historiografía de la filosofía en México, tal reflexión contenía o contuvo mucho más originalidad en el mundo eidético novohispano, que el de la tan buscada y exigua parcela de la modernidad de los historiógrafos de la filosofía en México. 
BIBLIOGRAFÍA

Aguirre Beltrán, G., La población negra de México: estudio etnohistórico. [ $1^{\mathrm{a}}$ ed., 1946] 2a ed., México, FCE, 1984 (Colección Tierra Firme).

, "Bailes de negros", Revista de la UNAM, vol. 25, núm. 2, octubre 1970.

Alamán, Lucas, Historia de México, $3^{\mathrm{a}}$ reimp, 5 t., México, Jus, 1942.

Bamunoba, Y. K. y B. Adoukounou, La muerte en la vida africana, Barcelona, Serbal, UNESCO, 1984.

Baqueiro Foster, G., Historia de la música en México: la música en el periodo independiente, México, SEP/INBA, Depto. de Música Sección de Investigaciones Científicas, 1964.

Barnet, Miguel, Biografía de un cimarrón, México, Siglo XXI, 1978. CAMPOS, RuBÉN M., El folklore y la música mexicana, México, SEP, 1928.

CArroll, PAtrick, "Los mexicanos negros, el mestizaje y los fundamentos olvidados de la 'raza cósmica': una perspectiva regional", en Historia Mexicana, México, COLMEX, 1995, v. XLIV, 3.

CAStro Gutierrez, F., Nueva ley y nuevo rey: reformas borbónicas y rebelión popular en Nueva España, México, IIH-UNAM, 1996.

Copleston, Frederick, "Nietzsche" en Historia de la Filosofía; de

Fichte a Nietzsche, Barcelona, Ariel, 1983, v. 7.

Estudios de historia de la Filosofía en México, México, UNAM, 1980. Gallegos Rocafull, José M., El pensamiento mexicano en los siglo XVI Y XVII, FYL-UNAM, 1951.

Gaos, José, "Lo mexicano en filosofía", Thesis, año 1, núm. 3, unAM, octubre 1979, pp. 5-14.

Griaule, Marcel, Dios del agua, Barcelona, Alta Fulla, 1987.

HÄBERMAS, J., "Un epílogo (1968) sobre la teoría del conocimiento de Nietzsche", en La lógica de las ciencias sociales, Madrid, Taurus, 1976. 
Hegel, G. F., Filosofía de la historia universal, trad. del alemán de J. Gaos, Madrid, Revista de Occidente, 1928, t. 2, p.195 "África". Historia de las religiones: los pueblos sin tradición escrita, México, Siglo XXI, 1982, t.11.

León Portilla, Miguel, La filosofía náhuatl..., $2^{\mathrm{a}}$ ed., México, unam, 1977.

MALLART, LUIS, "La medicina popular africana", en Las razas humanas, Madrid, Compañía Internacional Editora, 1984, vol. 3.

Motta SÁnchez, J. Arturo, "Huellas bantú en el nordeste del estado de Oaxaca", en María Elisa Velásquez y E. Correa [coords.], Población y culturas con herencia africana en México. Retos y perspectivas, México, INAH, 2005 (Africania, 1).

y María Elena Velásquez, "El retablo de Ayotla..., ¿obra del mulato esclavo carpintero...", Antropología. Boletín del INAH, Nueva Época, núm. 60, octubre-diciembre, 2000.

, "Un bozal en el ingenio de San Nicolás Ayotla, Teotitlán, Oaxaca", Dimensión Antropológica, año 8, vol. 22, mayo-agosto, 2001

Nietzsche, Federico, Crepúsculo de los ídolos, Madrid, Alianza, 1973. , Ecce homo, México, Editores Mexicanos Unidos, 1978. , La genealogía de la moral, Madrid, Alianza, 1981. , Asi hablaba Zaratustra, México, Editores Mexicanos Unidos, 1980.

Paz, Octavio, El laberinto de la Soledad; Postdata; Vuelta a El laberinto de la soledad, México, FCE, 1993 (Col. Popular, 471).

Pérez-Marchand, Monelisa, Dos etapas ideológicas del siglo XVIII en México a través de los papeles de la Inquisición. México, COLMEX, 1945.

Power, Eileen, Gente de la edad media, Londres, Penguin Books, 1937 [trad. al español Buenos Aires, Eudeba, 1966].

Priore, M. y Venancio Pinto, Ancestrais: uma introducao a historia da Africa Atlántica, Río de Janeiro, Elsevier, 2004. 
Ramos, Samuel, El perfil del hombre y la cultura en México, Argentina, Espasa-Calpe, 1951.

ROSNY, ÉRIC DE, Ojos que ven en la noche: un jesuita iniciado en la tradición africana, trad. de J. M. López de Castro, Barcelona, Herder, 1998, 267 pp.

Rovira, G. MARÍA DEL CARMEN. "Algunas reflexiones sobre el pensamiento filosófico en México en el siglo XVIII: (La influencia del pensador portugués Luis Antonio Verney en Fr. B. Díaz de Gamarra y Dávalos), Teoría. Anuario de Filosofía, México, Fyl-UnAM, año 1, núm. 1, 1980, pp. 185-196.

SALDÍVAR, GABRIEL, "El jarabe, baile popular mexicano" [s.l., s.e. s.a.] [nota al pie del autor: "sirvió de base a esta monografía la conferencia sustentada por el autor en la Sala de Conferencias y Conciertos del Palacio de Bellas Artes, el día 30 de noviembre de 1934]. , Historia de la música en México, en colaboración de Elisa Osorio Bolio, ed. facs. de la de 1934. /Mario Colín [ed.], México, Gobierno del Estado de México, 1981 (Biblioteca Enciclopédica del Estado de México).

Toro, Alfonso, "Influencia de la raza negra en la formación del pueblo mexicano", Ethnos, . t. I, núm. 8-12, México, 1920-1921, pp. 215-218.

Tshiamalenga, Ntumba, "Die Philosophie in der aktuellen Situation Afrikas", Zeitschrift für philosophische Forschung, vol. 33, 3 (1979), pp. 428-443 [Citado por Franz Martin Wimmer].

, ¿Existe un mito del mito?”, Diógenes, 1985, núm. 137, UNAM, pp. 113-135.

Villegas, Abelardo, La filosofía de lo mexicano, México, unam, 1988.

VILloro, LuIS, El proceso ideológico de la revolución de Independencia, $2^{a}$ ed., México, 1966 [reimpr. 1977].

, "Las corrientes ideológicas en la época de la Independencia", Estudios de historia de la Filosofía en México, México, unAm, 1980 . 
, "José Gaos y el giro de la filosofía latinoamericana", Dianoia v. XLI, núm. 47, noviembre, 2001.

Werner, Alice, Myths and legends. 1933. En http:www.sacredtexts.com/afr/index.htm [bajado en 14/07/2002]

WiMMER, Franz MARTIN, "Filosofía intercultural ¿nueva disciplina o nueva orientación de la filosofía?", Revista de filosofía, v. XXXIII (80), Costa Rica, San José, 1995, pp. 7-19.

Wiredu, Kwasi and Gyekye Kwame, Person and Community: Ghanaian philosophical Studies, I. /ed. George F. McLean. CIPSH/UNESCO (the council for research in values and philosophy cultural heritage and contemporary change series II. Africa). 1992.

Zea, Leopoldo. "Crisis del sentido de la historia occidental", Thesis. Nueva Revista de Filosofia y Letras, núm. 1, abril, 1979. , "Historia de las ideas e identidad latinoamericana", Teoría. Anuario de Filosofía, año 1, núm. 1, México, UNAM, 1980. 